\title{
Risk sensitive landscape planning and design: case study of the Prince Islands, Istanbul
}

\author{
F. A. Turer Baskaya \\ Department of Landscape Architecture, Faculty of Architecture, \\ Istanbul Technical University, Turkey
}

\begin{abstract}
With a population of 14 million, Istanbul is the biggest and probably the bestknown Turkish city. However, it is also one of the most hazard-prone cities due to the existence of the active North Anatolian Fault which runs under the Sea of Marmara. This fault poses a serious earthquake threat to the entire city, in particular its southern coastal districts of Istanbul. This study examines the southern Adalar district which has a total area of $11.3 \mathrm{~km}^{2}$ and which contains the nine Prince Islands. These islands have a history dating back to Byzantine times and have a rich cultural and natural landscape. Due to their popularity in terms of tourism and recreation, the Prince Islands experience seasonal demographic changes which range from 14,200 to 140,000 and this demographic shift brings additional concern for the adequacy of current emergency response protocols. In order to reveal the role of landscape architecture within the multidisciplinary setting of disaster management, this study utilizes GIS technology to examine the interplay between a potential Istanbul earthquake and the urban features of the Adalar district. This study's analysis of the Prince Islands' urban facilities, open spaces, touristic and recreational nodes, street patterns, building configurations, mental maps, and vegetative formations reveals the inadequacy of standard disaster management techniques. In addition, this study is an attempt to highlight the importance of risk sensitive landscape planning and design for Istanbul and other hazard-prone coastal cities through the development of planning and design strategies for the Prince Islands.
\end{abstract}

Keywords: landscape planning and design, earthquake, Istanbul, Prince Islands. 


\section{Introduction}

With a population of 14 million, Istanbul is the biggest and probably the bestknown Turkish city. However, due to the existence of the active North Anatolian Fault laying under the Sea of Marmara, it is also one of the most hazard-prone coastal megacities in the world. There is a $2 \%$ annual probability of occurrence of a magnitude $7+$ earthquake along this fault [1], and the southern coastal districts of Istanbul are in danger both from the earthquake itself and also from any secondary effects such as tsunami, fires and landslides.

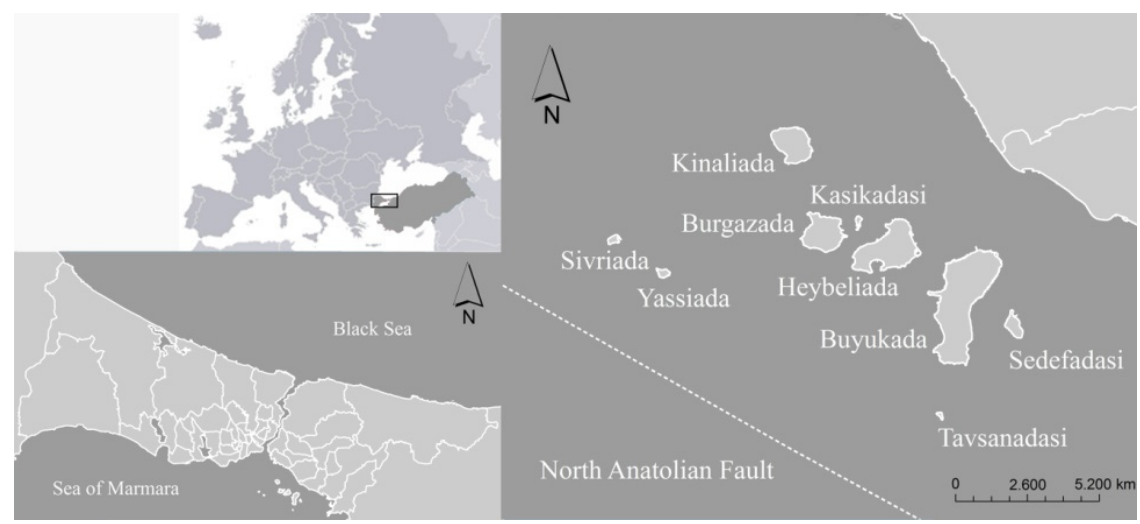

Figure 1: $\quad$ Location of the Prince Islands.

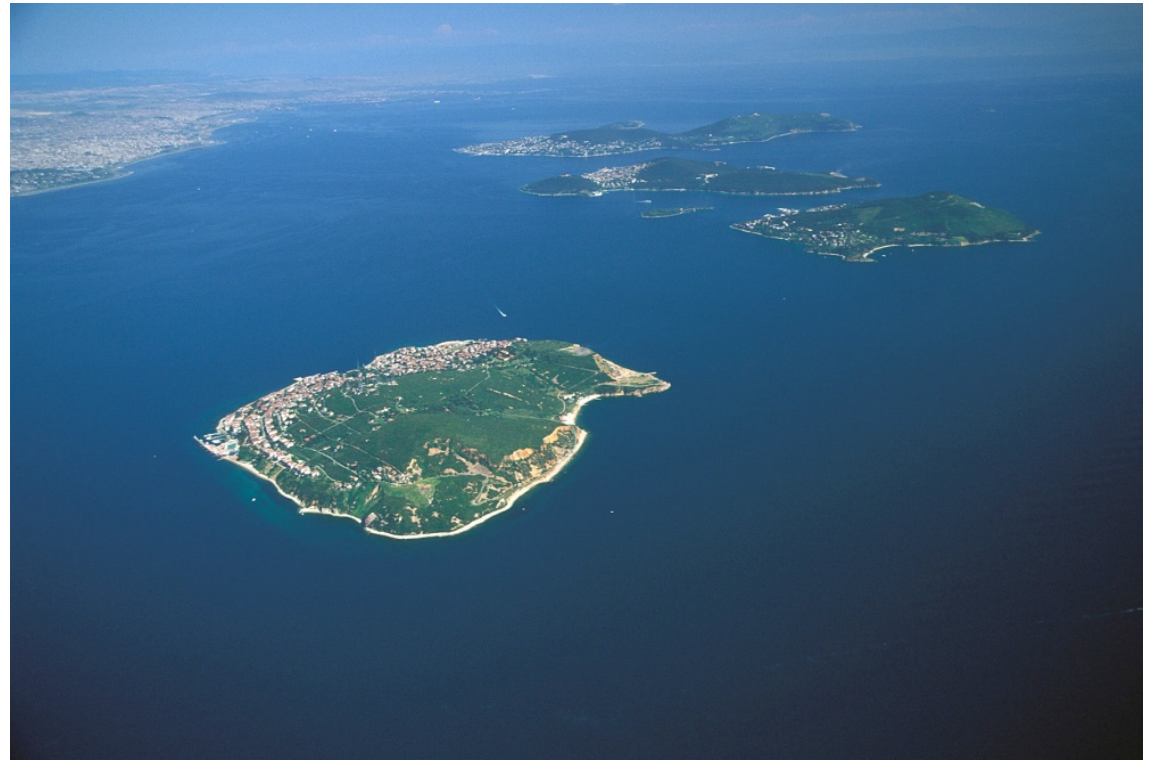

Figure 2: $\quad$ View of the Prince Islands from the north-west [2]. 
This study examines the Adalar district, which is the closest southern district to the North Anatolian Fault (Fig. 1). This district has a total area of $11.3 \mathrm{~km}^{2}$ and contains the nine Prince Islands [3]. These islands have a history dating back to Byzantine times and have a rich cultural and natural landscape (Fig. 2). Due to their popularity in terms of tourism and recreation, the Prince Islands undergo a large seasonal demographic shift which brings additional concern for the adequacy of current emergency response protocols.

Several comprehensive official risk analyses and mitigation studies have been conducted for Istanbul. These include the "disaster prevention/mitigation basic plan", the "production of microzonation report and maps", and the "earthquake master plan". However, any spatial implementation relevant to these theoretical studies is still lacking due to the fact that Istanbul is a rapidly changing city and official plans cannot always keep abreast of developments.

The Prince Islands have several natural and cultural conservation areas which minimize the opportunity for spatial alterations. However, even the Conservation Development Master Plan for the Prince Islands of 2010 cannot be claimed to represent the current circumstances. Multi-scale studies are essential for the identification and implementation of accurate disaster mitigation strategies, and their absence has prompted this study, which is an examination of the role of landscape architecture within the multi-disciplinary setting of disaster management.

This study examines open space characteristics and overall urban features to determine holding capacities with the purpose of producing landscape planning and design strategies for the pre- and post- earthquake periods. It examines each of the Prince Islands through a multi-layered approach and looks at the different phases of disaster management.

\section{Materials and methods}

In order to establish the effect of a potential earthquake on the Prince Islands, this study utilized GIS technology and ArcGIS 10.0 software to examine urban landscape elements as well as facilities and infrastructure. 1:1000 digital base map files in dwg format and the emergency plan for the Prince Islands were obtained from the Adalar Municipality. Aerial photographs and additional information for the dispersion of urban facilities were obtained from the online city map service of the Adalar Municipality. The fieldwork was conducted from September 2014 to November 2014.

Within this study, GIS-based data was registered to Universal Transverse Mercator 3 Degree coordinate system with European Datum 1950 as the disaster mitigation based studies for Istanbul [4] refer to this coordinate system. Further information regarding a potential Istanbul earthquake and its impact on the Adalar district was obtained from the literature during the development of this study. 


\section{Results and discussion}

This study examines the interplay between a potential Istanbul earthquake and the inhabited islands of the Adalar district (Fig. 3). Final Report for the simulation and vulnerability analysis of tsunamis production for the Asian side to Istanbul Metropolitan Municipality asserts that the eastern coasts of the city are more at risk than the western ones, and that the highest run-up height exceeding $9 \mathrm{~m}$ is expected to hit the Prince Islands [5]. In addition, the Executive Report for the production of microzonation maps for the Asian side of Istanbul predicts runup heights from $3 \mathrm{~m}$ to $10 \mathrm{~m}$ for the Prince Islands [6].

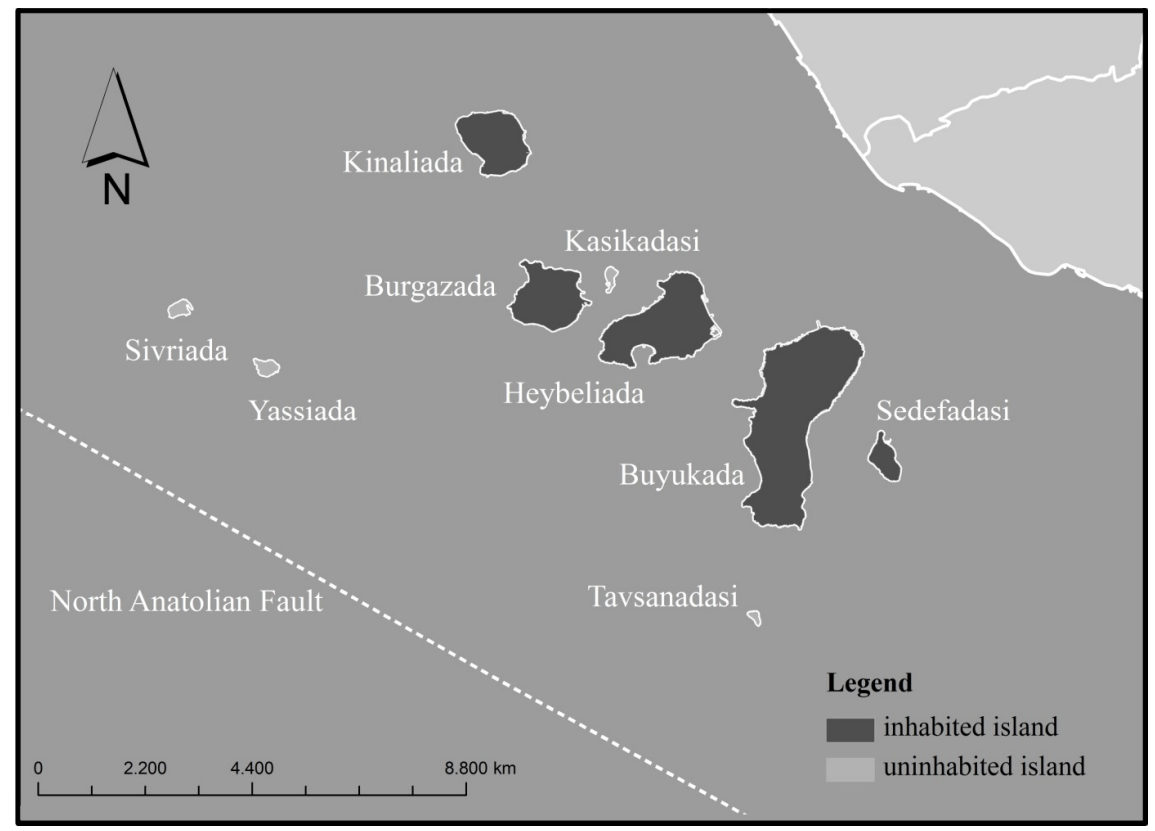

Figure 3: The Prince Islands and the location of the North Anatolian Fault.

There is no available tsunami inundation map for the Adalar district. Therefore, a contour line of $10 \mathrm{~m}$ is given in Fig. 4 to illustrate the interplay between the run-up height and the dispersion of urban facilities and infrastructure.

During the post-earthquake period, the Sea of Marmara will become an important means of transportation for all of the coastal districts. However, there is a serious concern about the impact of a tsunami on vessels and transportation nodes such as docks, piers and ports.

The disaster-based studies for Istanbul focus on district-scale evaluations and estimates, but the Adalar district is a specific case as it consists of five inhabited islands within the Sea of Marmara. The inhabitants of the islands benefit from 


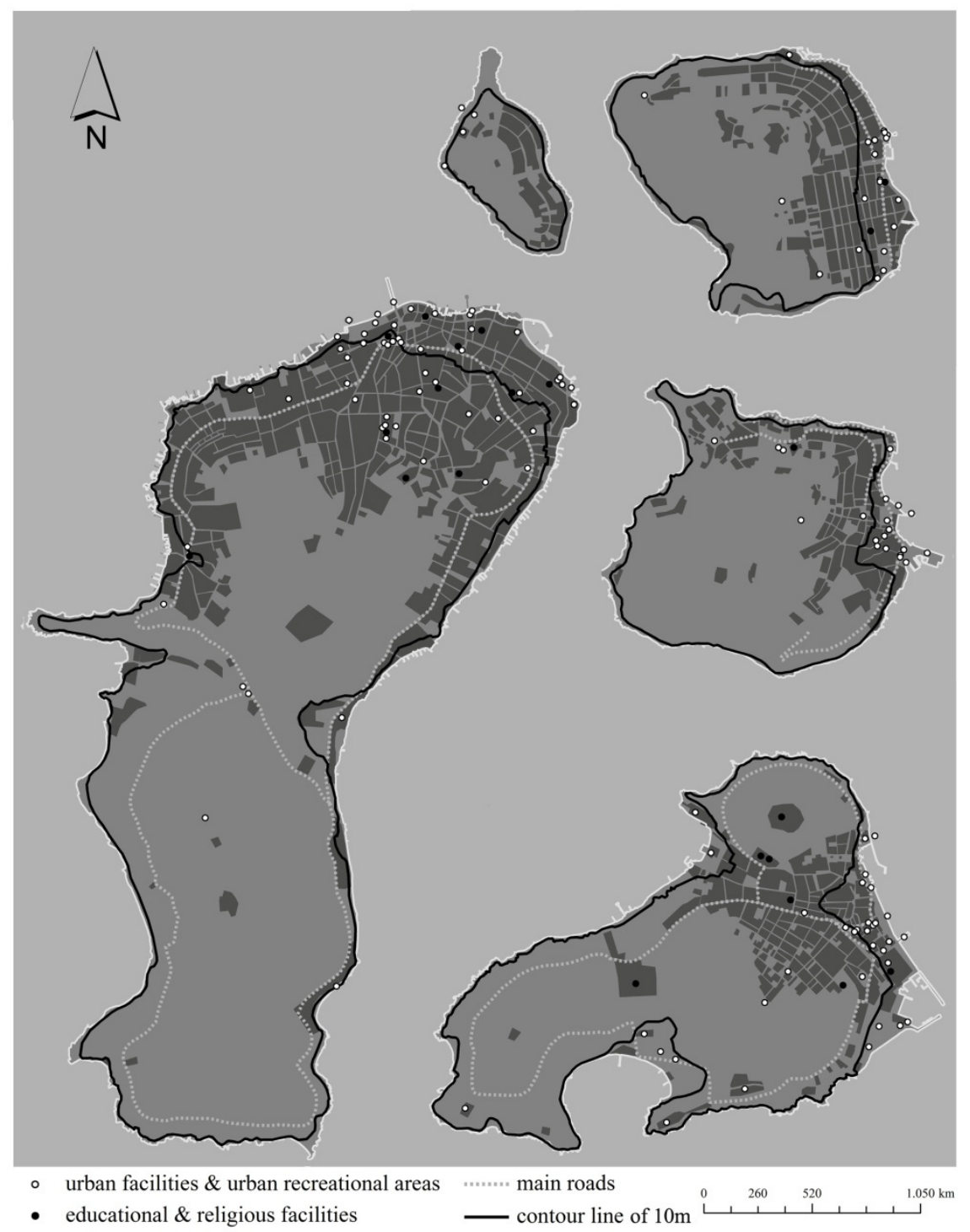

Figure 4: Dispersion of urban facilities and urban recreational areas.

the facilities dispersed across the islands for their daily practices and needs, and these constitute a base for the collective memory which binds these islands together, both socially and psychologically. Although the Prince Islands are politically and psychologically bound to each other, they have geographical barriers separating them. In the aftermath of an earthquake, the water which generally acts as a vital medium binding them to each other, will become a 
physical barrier that will oblige them to stand alone until the arrival of emergency teams and aid.

Many of the islands' inhabitants work on the mainland and therefore rely on public and private ferries, sea-buses and boats [7]. A majority of the employees of the Adalar Municipality also rely on these transportation services as it is impossible for all of them to live on Buyukada, the seat of the islands' administration. The employees of the administrative and health-care facilities will bear the initial responsibility for the emergency response period, but these people will also be counted among the victims of the earthquake. Contact by sea will be important for all of Istanbul's inhabitants in the aftermath of an earthquake. For the people living on the mainland, the "sea connection" connotes contact with aid teams in addition to it being an alternative to the anticipated blocked roads. In the case of the Prince Islands, the "sea connection" is a more complicated issue; it must be expected that there will be a large number of tourists aiming to leave while the inhabitants of the islands who are working on the mainland will demand a means to reach their families.

Figure 4 shows urban facilities such as administrative units, transportation units, health-care facilities and infrastructure units. The GIS-based mapping carried out for this study indicates 33 administrative units, even including security facilities (Fig. 4). Among these, only 10 are above an elevation of $10 \mathrm{~m}$, which gives rise to concern for the post-earthquake period as the official documentation recommends sub-district administrative units as initial gathering places for inhabitants. The Adalar district has five sub-districts, but only one of these administrative units has any open space and all of them are at risk from the projected tsunami.

The GIS-based mapping carried out for this study indicates 21 health-care units (Fig. 4), but two of these units are the buildings of the Heybeliada Sanitarium, which is out of service. Community clinics and pharmacies constitute 18 units, and there is only one hospital in the Prince Islands. The Disaster Mitigation Basic Plan for Istanbul estimates the rate of heavily injured people to be $74 \%$ for the islands; this figure is considerably higher than the $35 \%$ calculated for the second highest [4].

The 1:5000 Adalar Conservation Development Master Plan of 2010 states that the island of Heybeliada has the most advantages due to its health-care facilities. However, this plan includes the Heybeliada Sanatorium, which has been closed since 2005 [3]. Today, the only hospital of the Prince Islands exists on Buyukada. Such issues illustrate the serious healthcare problem in the Adalar district; the current facilities are insufficient for the inhabitants of the islands even though the district can also welcome thousands of tourists each day.

Although the islands' educational and religious facilities are also regarded as urban facilities, they are marked with a different symbol due to the emergency roles they are expected to take in the aftermath of a disaster. In the aftermath of a disaster, these two facilities will leave their own functions and gain emergency ones due the necessities. This map only illustrates the Muslim religious facilities due to their public identity. Mosques have very limited open space when they are 
compared with Christian religious buildings, but many of these buildings are non-functional today.

Educational facilities within large parcels hold important open spaces within dense built-up spaces. In addition, these educational facilities' availability during the emergency response period should be evaluated according to the age of the building, its construction type and any necessity for retrofitting.

Urban recreational areas include open spaces and active recreational areas inside built-up districts such as squares, district parks, sports areas and clubs. These open spaces may become gathering places in the aftermath of an earthquake.

The GIS-based mapping carried out for this study indicates 16 district parks. However, the majority of these parks have got very limited areas and significant elevation differences. At the first glance, sports areas may be regarded as being available for the emergency response period as they are flat open spaces. However, in the case of the Adalar district, these are too close to the coastline.

The total area of the Adalar district is 1133,66 ha. Forest areas constitute $55 \%$ of this while residential areas constitute $28 \%$ [3]. Although there is a vast amount of forest on the islands, the scarcity of urban open space presents a problem as these spaces will be important during the early post-earthquake period. Unlike rural open spaces such as forests, urban open spaces are equipped with infrastructure and allow active spatial uses. Forests are defined as passive green areas as their main function is not recreation, therefore "active" refers to "recreation" and the accompanying "infrastructure". Forests also involve some active spaces such as picnic areas and plages, but their distance from built-up spaces eliminates them from being used during an emergency.

Residential type in term of garden size is another important issue for the postearthquake period, and there are large numbers of villas on the islands. In cases of such houses with low to medium damage, the owners may prefer to use their private gardens in the aftermath of an earthquake.

Motorized vehicles are forbidden on the Prince Islands. The current road network is only available for horse-drawn carriages and bicycles. The administrative facilities have only a limited number of motorized service vehicles.

According to the Disaster Mitigation Basic Plan for Istanbul, 80.5\% of the roads on the Prince Islands are narrower than $6 \mathrm{~m}$. These narrow streets are vulnerable to blockage from collapsed buildings if there is an earthquake. The debris from collapsed and damaged buildings within the Adalar district is estimated at 839,000 tons [4]. Due to the historical background of these islands, masonry buildings constitute $47.6 \%$ while wooden ones constitute $10.6 \%$ [3].

The panoramic view of Istanbul has been one of the most important factors in the configuration of the current built-up space, and has resulted in narrow roads with high slopes and stairs. The hilly topography, narrow street patterns, old built-up spaces and insufficient number of vehicles should be taken into consideration when formulating any emergency response for the Adalar district.

District scale evaluations for disaster mitigation take the number of inhabitants into consideration. However, these evaluations are defective both for 
islands and touristic districts. Significant seasonal demographic changes occur in the Adalar district and secondary residences constitute $52 \%$ of the whole housing supply [3]. The existence of secondary residences increases the winter population of 14,200 to 72,000 during the summer; together with daily visitors this summer figure reaches to 140,000 [7]. It is therefore important to develop emergency response plans which account for seasonal demographic changes.

The difference between the mental maps of the islands' inhabitants and visiting tourists should also be regarded during the emergency period. In case of an earthquake, tourists will rush to transportation nodes, and their preferred routes will relate to their mental maps. They examine the islands through recreational-touristic areas and landmarks, and the dispersion of these reveals their mental maps and the risks they will face.

Figure 5 shows 86 tourism and 67 recreation spots including hotels, pensions, museums, socio-cultural centres, beaches, picnic areas, urban recreation areas, as well as cultural conservation units such as historical residences, and the religious buildings of Christians and Jews.

GIS mapping carried out for this study indicate 45 hotels and pensions, and 29 of them are between the $10 \mathrm{~m}$ contour and the coastline. On the inhabited islands, the religious facilities are numerically significant as they include 27 churches and monasteries, two synagogues, and seven mosques.

While attempting to benefit from these facilities to establish a network during the emergency response period is worthwhile, there is also a concern regarding the durability of these buildings due to their age. Besides the other natural and cultural heritage units, these religious units bring about a tourism relying on historical religious buildings and complexes. There are some monumental religious buildings with large open spaces which may be transformed into the main components of an emergency plan. Retrofitting these historical units is essential for the continuity of cultural heritage, the psychology of local people and the protection of disaster victims gathering in their open spaces. However, due to their identity and ownership, these monumental buildings and complexes should be systematically evaluated even regarding the confirmations from the related association so that they can be utilized and become multi-functional during the post-earthquake period.

For the emergency response period, establishing a road network to bind the post-earthquake period functional areas to the transportation nodes is essential. An equilibrium should be established between the parameters for "minimum distance", "width and slope of the roads", and "durability of the buildings along the roads".

Besides the tsunami, building collapse and the destruction of transportation nodes, there are also secondary hazards such as fires and landslides. Fire presents a particular danger as the Prince Islands have maquis vegetation, mostly coniferous forests, which would be very susceptible to sparks from the urban areas. Therefore, fire control techniques which are not only equipment-based but which also include landscape interventions should be implemented during the pre-earthquake period. 


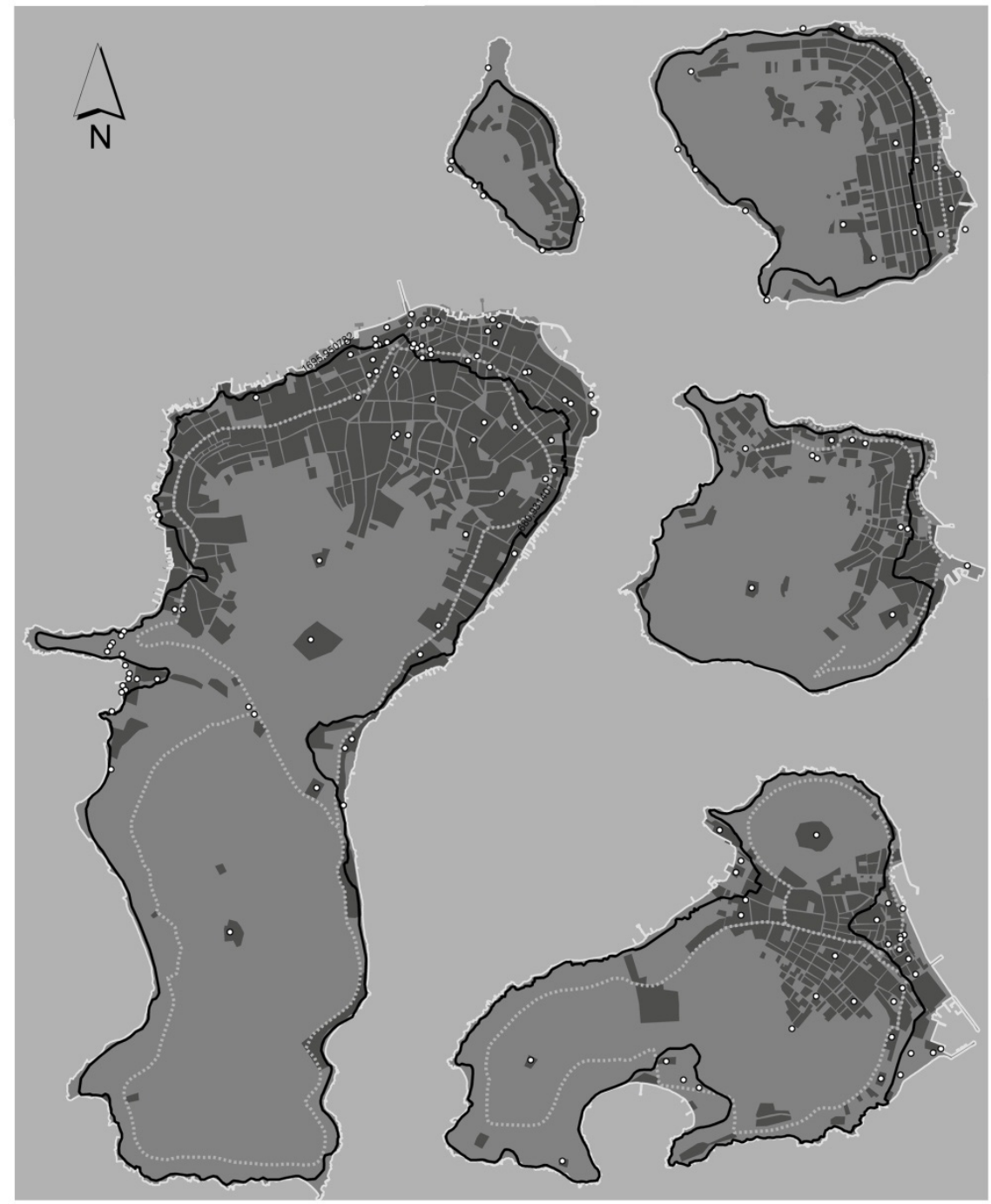

- tourism \& recreation

main roads

- contour line of $10 \mathrm{~m}$

$1.040 \mathrm{~km}$

Figure 5: Dispersion of touristic and recreation areas.

Landslides are another potential event which may be triggered by an earthquake. The southern region of Burgazada and the southwest area of Heybeliada are considered to have a low landslide risk, while the southwest region of Buyukada is considered to have a landslide risk that ranges from low to medium and high [6]. The locations of the monumental historical buildings with large open spaces and the emergency road network should be also evaluated with regard to these two secondary hazards. 


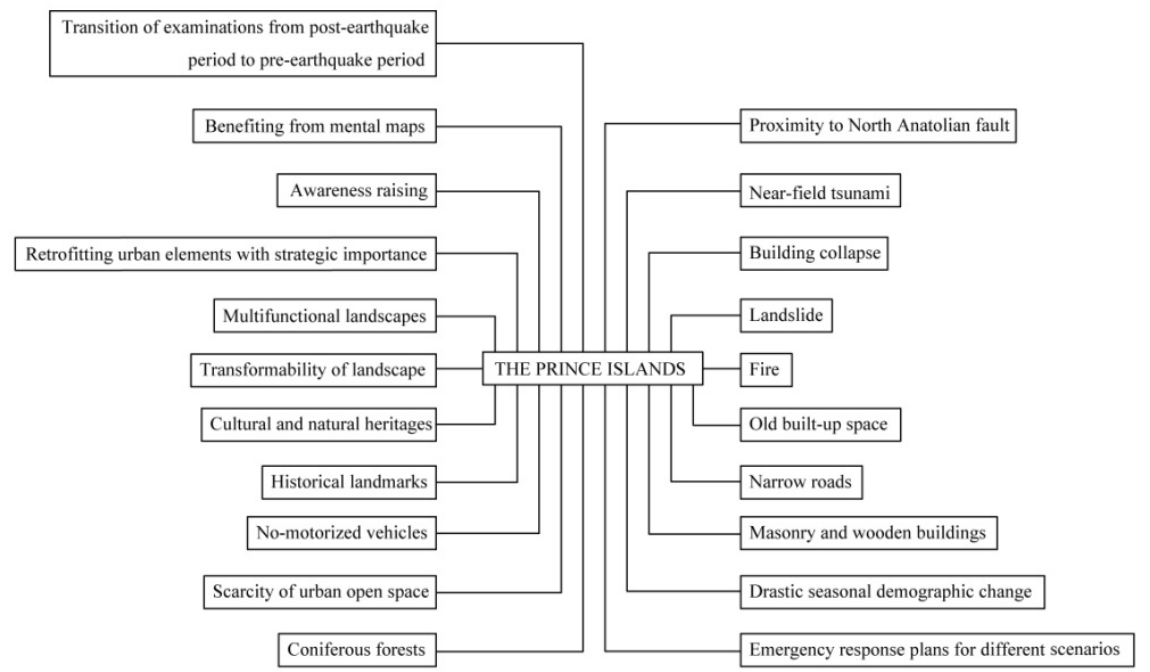

Figure 6: Relevant terms of the interplay between the Prince Islands and a potential Istanbul earthquake.

In addition to the benefits that the mental maps of the islands' inhabitants and tourists offer for the establishment of emergency routes, they also provide an opportunity to raise awareness during the pre-earthquake period. Landscape design enables open spaces to carry clues about their role in any emergency response. Through their everyday practices, people may absorb information about the emergency response by becoming familiar with embedded signs and symbols.

The evaluations conducted within this study have produced a list of terms for risk-sensitive landscape planning and design strategies (as shown in Fig. 6).

\section{Conclusion}

This study examines the interplay between a potential Istanbul earthquake and the urban features of the Adalar district, and proposes multi-scale strategies for the pre-earthquake period by using scientific estimates for the post-earthquake period. Scrutiny of the characteristics of the urban facilities, open spaces, touristic and recreational nodes, street patterns, building configurations, mental maps, and vegetative formations reveals that customary disaster management techniques are defective in the case of the Prince Islands.

Through the development planning and design strategies for the Prince Islands, this study is an attempt to highlight the importance of risk sensitive landscape planning and design for Istanbul and other hazard-prone coastal cities. 


\section{References}

[1] Erdik, M., Demircioglu, M., Sesetyan, K., Durukal, E., and Siyahi, B., Earthquake hazard in Marmara Region, Turkey, Soil Dynamics and Earthquake Engineering, 24, 605-631, 2004.

[2] Eurosoft, CD for digital Istanbul photographs- free of copyright, 2005.

[3] 1:5000 Adalar Conservation Development Master Plan, Plan Report, 2010 http://www.adalar.bel.tr/site-images/PlanRapor_Cilt1_2_kurul.pdf

[4] JICA \& IMM, The study on a disaster prevention/mitigation basic plan in Istanbul including seismic microzonation in the Republic of Turkey final report, Japan International Cooperation Agency and Istanbul Metropolitan Municipality, 2002 http://www.ibb.gov.tr/trTR/SubSites/DepremSite/ PublishingImages/JICA_ENG.pdf

[5] OYO International Co., Simulation and Vulnerability Analysis of Tsunamis Affecting the Istanbul Coasts, Final Report to Istanbul Metropolitan Municipality, Directorate of Earthquake and Ground Investigation, Istanbul, 2007.

[6] OYO International Co., Production of microzonation report and maps for Asia side to Istanbul Metropolitan Municipality, Executive Report, 2009 http://www.ibb.gov.tr/tr-TR/SubSites/DepremSite/Documents/Asian_ microzonation\%20prj_summary.pdf

[7] Official web page of the Adalar Municipality, http://www.adalar.bel.tr /nufus.asp 